\title{
Effect of Galla Chinensis on Remineralization of Early Dentin Lesion
}

\author{
Hend Mahmoud Abdel-Azem ${ }^{1}$ Ahmed Fawzy Abo Elezz ${ }^{2} \quad$ Rehab Khalil Safy ${ }^{2}$ \\ ${ }^{1}$ Restorative Department, Faculty of Dentistry, Suez canal \\ University, Ismailia, Egypt \\ ${ }^{2}$ Department of Restorative Dentistry, Faculty of Dentistry, Suez \\ Canal University, Ismailia, Egypt

\begin{abstract}
Address for correspondence Hend Mahmoud Abdel-Azem, Canal University, Ismailia 0064, Egypt (e-mail: hendrashwan13@gmail.com).
\end{abstract} \\ Department of Restorative Dentistry, Faculty of Dentistry, Suez
}

Eur J Dent:2020;14:651-656

\begin{abstract}
Objective To investigate the efficacy of the Galla chinensis extract (GCE) on early dentin lesion remineralization.

Materials and Methods Seventy-two dentin specimens were divided into three groups according to the treatment solution. In group S1, specimens were treated with GCE; in group S2, the specimens were treated with sodium fluoride ( $\mathrm{NaF}$ ); meanwhile, specimens of group S3 were treated with distilled water (DW). Each group was further subdivided into two subgroups according to the treatment time (1 minute and 5 minutes). An in vitro $\mathrm{pH}$-cycling model for 12 days was done. Subsequently, surface microhardness (SMH) of the specimens, elemental analysis, and their micromorphological appearance were evaluated.

Statistical Analysis Data were statistically analyzed. One-way analysis of variance was used to compare numerical (parametric) data between more than two separate groups followed by post hoc Tukey.

Results There was no significant difference between the mean $\mathrm{SMH}$ of dentin between NaF and GCE groups. Regarding the time, the 5-minute treatment with NaF and DW groups recorded higher mean SMH value of dentin than the 1-minute treat-

Keywords

- dentin

- demineralization

- remineralization

- GCE ment group. Meanwhile, for GCE groups, the 1-minute immersion recorded higher mean $\mathrm{SMH}$ value than the 5 -minute immersion without any significant difference between them. The microhardness results were confirmed by environmental scanning electron microscope and energy dispersive $\mathrm{X}$-ray analysis results.

Conclusion GCE could be used as an effective alternative for dentin remineralization.
\end{abstract}

\section{Introduction}

Dental caries is the consequence of multiple episodes of demineralization and remineralization, rather than a one-way cycle of demineralization. ${ }^{1}$ The detailed understanding we have of the dental caries protocol at the moment makes it possible at an earlier stage to compile steps to identify dental caries and to determine the ability of new materials to avoid demineralization or, even better, promote remineralization. ${ }^{2}$ The anticaries effect of fluoride has been demonstrated in numerous clinical and laboratory studies over the past decades, which has shown its caries-prophylactic influence through a positive change in the demineralization/remineralization balance. ${ }^{3-5}$ Despite the fact that the cariostatic effect of fluoride, that is, demineralization suppression, encouraging remineralization of the incipient lesions was well known, a variety of opinions on the use of fluoride exist. ${ }^{4}$ Fluoride has a significant effect on caries diffusion but is far from completely recovering. Additionally, fluoride can cause fluorosis by overexposure ${ }^{6,7}$ and despite the fact that fluoride does not adversely affect the ordinary person, when used properly, it was suggested that fluoride exposure should be restricted among certain groups. ${ }^{8}$ Accordingly, alternate, effective nonfluoride anticaries agents still need to be searched for. Several past studies had looked for
DOI https://doi.org/

$10.1055 / \mathrm{s}-0040-1716778$

ISSN $1305-7456$.
License terms

()(1) $\Theta \circledast$ 
other synthetic materials, which have a better effect than fluoride. However, some research has shown that the combination of fluoride and other elements may have a greater effect on the prevention of dental enamel demineralization. ${ }^{9,10}$ As a result, several studies have concentrated on the search for alternative successful natural agents.

Lately, various studies examined Galla chinensis extract (GCE), a natural nontoxic traditional Chinese herbal medicine. Further researches had reported the anticariogenic impact of GCE and its capability of GCE to positively activating enamel remineralization. ${ }^{11-15}$ This effect is credited to GCE enamel organic matrix interaction, ${ }^{16,17}$ so that, considering that dentin contains more organic matrix than enamel, GCE could result in better remineralizing effect on dentin in comparison to enamel..$^{18}$ As research on GCE's remineralization of early dentin lesions is limited, an in vitro $\mathrm{pH}$-cycling model will therefore be used in the current study to estimate GCE's ability to remineralize early dentin lesions.

\section{Materials and Methods}

\section{Specimens' Preparation}

A total of 72 intact, sound, freshly extracted permanent human mandibular second molar teeth (extracted for periodontal reasons) were selected for the study. The age range of patients was 45 to 55 years. ${ }^{19}$ All teeth exhibiting any signs of caries, microcracks, or other defective structure were discarded. The collected teeth were stored in normal saline plus $0.5 \%$ thymol as antifungal agent until being used no longer than 3 months. ${ }^{20}$ The utilization of extracted human teeth was confirmed by the research ethics committee of the Faculty of Dentistry, Suez Canal University, Egypt.

A diamond saw under water irrigation (IsoMet 4000 saw Buehler, United States) was used for preparing 72 dentin specimens. The dentin specimens were embedded in self-cure acrylic resin and allowed to set to create dentin blocks. The specimens were randomly divided into 60 specimens for microhardness measurement and 12 specimens for environmental scanning electron microscope (ESEM) and energy dispersive X-ray (EDX) measurement. The 60 specimens of microhardness test (MHT) were again randomly divided into three groups according to treatment solutions $(n=20)$; in group S1, specimens were treated with aqueous solutions of GCE. In group S2, the specimens were treated with an aqueous solution of sodium fluoride $(\mathrm{NaF})$ (the positive control group) (-Table 1); meanwhile, specimens of group S3 were treated with distilled water (DW) (the negative control group). Each group was further subdivided into two subgroups according to the treatment time of dentin specimens in each solution (T) $(n=10):$ T1, 1 minute and T2, 5 minutes. Meanwhile, ESEM and EDX specimens were also randomly divided into three groups according to the previous treatment solutions $(S)(n=4)$. Each group was also randomly subdivided into two subgroups according to time of immersion $(\mathrm{T})(n=2)$. All dentin specimens were identified with numbers written on the base of the acrylic resin by permanent marker.

\section{The Baseline Surface Microhardness Test}

The baseline microhardness of the dentin specimens was taken at three different points. The indentations were made around $0.5 \mathrm{~mm}$ from the interface and $1 \mathrm{~mm}$ separated from each other. ${ }^{21}$ Each estimation was completed utilizing a 100 -g load for 15 seconds, connected perpendicularly to the dentin surface. One hardness value was produced from the averaged values for each specimen. Vickers microhardness tester was utilized to estimate the microhardness (Wilson miniaturized scale hardness analyzer, display Tukon 1102, Germany). Microhardness was acquired utilizing the accompanying equation: $\mathrm{HV}=$ $1.854 \mathrm{P} / \mathrm{d}^{2}$, where, $\mathrm{HV}$ is Vickers hardness in $\mathrm{Kgf} / \mathrm{mm}^{2}, P$ is the load in Kgf, and $d$ is the average length of the diagonals in $\mathrm{mm}$.

\section{Preparation of Artificial Carious Lesion}

All dentin specimens were immersed in a demineralized solution $\left(2.2 \mathrm{mM} \mathrm{Ca}^{2+}, 2.2 \mathrm{mM} \mathrm{PO}_{4}{ }^{3}\right.$, and $50 \mathrm{mM}$ acetic acid at a $\mathrm{pH}$ of 4.4) for 72 hours to induce artificial carious lesion. ${ }^{22}$ For standardization of the demineralized surface area of each specimen, an adhesive strip ( $3 \mathrm{~mm} \times 3 \mathrm{~mm}$ ) was attached to the surface of each specimen and two layers of acid-resistant nail varnish were used to cover the remaining surface. After demineralization time, specimens were removed and rinsed with DW. The 60 specimens of surface MHT were evaluated for demineralized surface microhardness (SMH).

\section{pH Cycling}

The cariogenic challenge for the 72 specimens was simulated through a modified pH cycle. Dentin specimens of GCE group (S1) were immersed in $4 \mathrm{~g}$ of aqueous solutions of GCE, dentin specimens of $\mathrm{NaF}$ group (S2) were immersed in $1 \mathrm{~g}$ aqueous solutions of NaF; meanwhile, specimens of S3 group were immersed in DW. In T1 subgroup, the immersion time in each solution was conducted for 1 minute, and in T2 subgroup,

Table 1 Materials, composition, manufacturer, and lot number

\begin{tabular}{|l|l|l|l|}
\hline Materials & Composition & Manufacturer & Lot number \\
\hline $\begin{array}{l}\text { Demineralizing } \\
\text { solution }\end{array}$ & $\begin{array}{l}2.2 \mathrm{mM} \mathrm{Ca}^{+2}, 2.2 \mathrm{mM} \mathrm{PO}_{4}{ }^{3} \text {, and } 50 \mathrm{mM} \\
\text { acetic acid at a pH of 4.4 }\end{array}$ & $\begin{array}{l}\text { Department of Chemistry, Faculty of Science, Suez } \\
\text { Canal University, Ismailia, Egypt }\end{array}$ & $\begin{array}{l}\text { Department of Chemistry, Faculty of Science, Suez } \\
\text { Canal University, Ismailia, Egypt }\end{array}$ \\
\hline $\begin{array}{l}\text { Remineralizing } \\
\text { solution }\end{array}$ & $\begin{array}{l}20 \mathrm{mM} \mathrm{NaH}_{2} \mathrm{CO}_{3}, 3 \mathrm{mM} \mathrm{NaH}_{2} \mathrm{PO}_{4} \text {, and } 1 \mathrm{mM} \text { at a pH of } 7 \\
\mathrm{GCE}\end{array}$ & $\begin{array}{l}\text { Bulk supplements, 7511 Eastgate Road, Henderson, } \\
\text { Nevada 89011, United States }\end{array}$ & $121 \mathrm{D0906}$ \\
\hline $\mathrm{NaF}$ & $98 \%$ pure NaF reagent grade fine powder & Eisen-Golden Laboratories & $7681-49-4$ \\
\hline
\end{tabular}

Abbreviations: GCE, Galla chinesis extract; NaF, sodium fluoride. 
for 5 minutes. The daily cycling regimen consisted of a test of 2 hours/d acid in the demineralized solution, followed by immersion of the specimen in the remineralized solution (20 $\mathrm{mM} \mathrm{NaH}_{2} \mathrm{CO}_{3}, 3 \mathrm{mM} \mathrm{NaH}_{2} \mathrm{PO}_{4}$, and $1 \mathrm{mM} \mathrm{CaCl}$ at a pH of 7) for $\sim 22$ hour/d ( - Table 1 ). Deionized water washed over the blocks. The $\mathrm{pH}$ routine has been repeated for 12 days. ${ }^{23}$

\section{Final Surface Microhardness Test}

After the $\mathrm{pH}$ cycling/treatment cycle had been completed, the $60 \mathrm{SMH}$ specimens were put in ultrasound to clean up any residual residues on their surfaces. Later, the final measurement of SMH was taken.

\section{Micromorphological Examination and Elemental Analysis}

The dentin specimens that were prepared for ESEM and EDX analysis were placed in ultrasound for cleaning any remaining residue on their surfaces. The dentin surface micromorphology and surface mineral contents of each specimen were assessed at baseline, after demineralization, and after the treatment. ESEM and EDX analysis (Quanta250 FEG, field emission gun) was operating at $30 \mathrm{kV}$ with secondary electron mode at 2,500 magnification.

\section{Statistical Analysis}

Statistical testing was performed using Windows, version 23 of IBM SPSS software. The degree of significance was set to $p$-value $<0.05$.

\section{Results}

\section{SMH Results}

- Table 2 demonstrates the effect of different immersing solutions on the mean SMH of dentin (mean \pm standard deviation [SD] and level of significance) for all groups. They demonstrate that the NaF recorded the highest mean value followed by GCE without any statistically significant difference between them. Meanwhile, DW group recorded the lowest mean value. Also, there was a significant difference between both of GCE, NaF and DW groups. Concerning the immersion time, immersion of specimens for 5 minutes in either NaF or DW recorded higher mean SMH values of dentin than the 1-minute immersion in the same solutions, with no statistically significant difference between both times for each group. Surprisingly, in GCE groups, the 1-minute immersion recorded higher mean SMH value of dentin than the 5-minute immersion with no statistical significant difference between both times.

\section{ESEM Results}

ESEM photomicrograph of sound dentin showed a homogenous smooth surfaces appearance. However, in the demineralized dentin, the ESEM photomicrograph showed widely opened dentinal tubules creating spongylike appearance with different shapes of opened dentinal tubules, some had circular shape and others were oval. The ESEM photomicrograph of DW-treated dentin specimen surfaces was similar to ESEM photomicrograph of the demineralized specimens. However, there was little obliteration of some dentinal tubules with mineral precipitations (-Fig. 1). Meanwhile, the photomicrograph representing $\mathrm{NaF}$ (-Figs. 2 and $\mathbf{3}$ ) and GSE (-Figs. 4 and $\mathbf{5}$ )

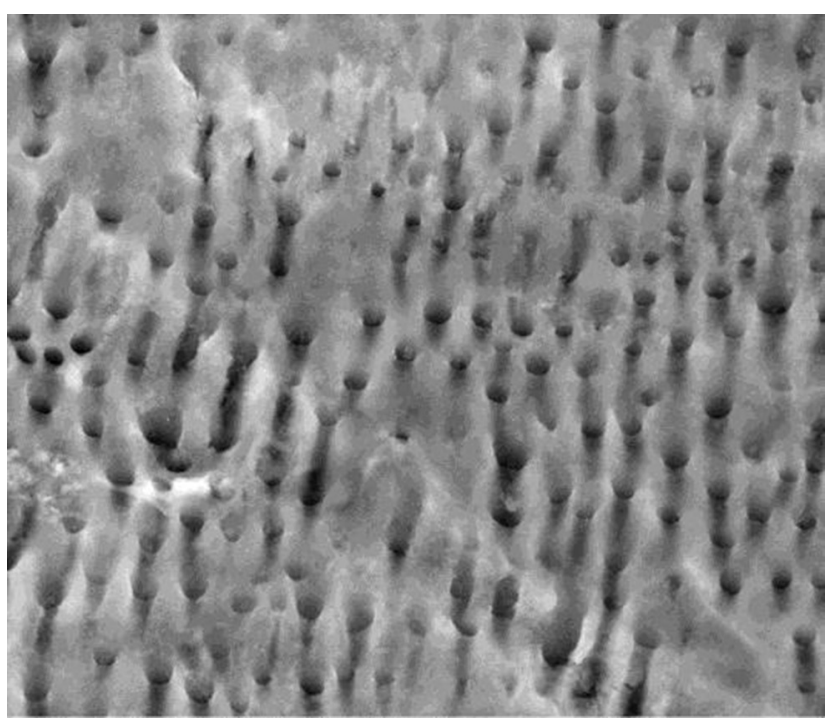

Fig. 1 Environmental scanning electron microscope showing dentin surface after treated with distilled water for 5 minutes.

Table 2 Effect of different immersing solutions on the mean SMH of dentin

\begin{tabular}{|c|c|c|c|c|c|c|c|c|c|c|}
\hline & & & & \multicolumn{3}{|c|}{ Testing solution } & \multirow{2}{*}{$\begin{array}{l}\text { ANOVA } \\
p \text {-Value }\end{array}$} & \multicolumn{3}{|c|}{ Post hoc } \\
\hline & & & & DW & $\mathrm{NaF}$ & GCE & & P1 & $\mathrm{P} 2$ & P3 \\
\hline \multirow[t]{6}{*}{ Time } & \multirow[t]{3}{*}{$1 \mathrm{~min}$} & Baseline & Mean \pm SD & $66.3 \pm 5.7$ & $65.2 \pm 3.9$ & $65.9 \pm 5.4$ & 0.27 & & & \\
\hline & & Demineralization & Mean \pm SD & $36.7 \pm 7.1$ & $35.7 \pm 5.2$ & $36.7 \pm 3.8$ & 0.9 & & & \\
\hline & & Remineralization & Mean \pm SD & $40.6 \pm 7.0$ & $58.7 \pm 4.6$ & $59.1 \pm 4.6$ & $<0.001^{\circ}$ & $<0.001^{*}$ & $<0.001^{*}$ & 0.97 \\
\hline & \multirow[t]{3}{*}{$5 \mathrm{~min}$} & Baseline & Mean \pm SD & $68.3 \pm 4.7$ & $67.8 \pm 5.4$ & $65.4 \pm 5.2$ & 0.08 & & & \\
\hline & & Demineralization & Mean \pm SD & $39.7 \pm 7.4$ & $38.6 \pm 5.6$ & $38.6 \pm 2.6$ & 0.05 & & & \\
\hline & & Remineralization & Mean \pm SD & $42.9 \pm 7.8$ & $61.0 \pm 5.1$ & $57.2 \pm 5.2$ & $<0.001^{\circ}$ & $<0.001^{*}$ & $<0.001^{*}$ & 0.1 \\
\hline
\end{tabular}

Abbreviations: ANOVA, analysis of variance; DW, distilled water; GCE, Galla chinensis extract; NaF, sodium fluoride; SD, standard deviation; SMH, surface microhardness.

Note: P1: significance between DW and NaF; P2: significance between DW and GCE; P3: significance between NaF and GCE.

*: Significance $<0.05$ 


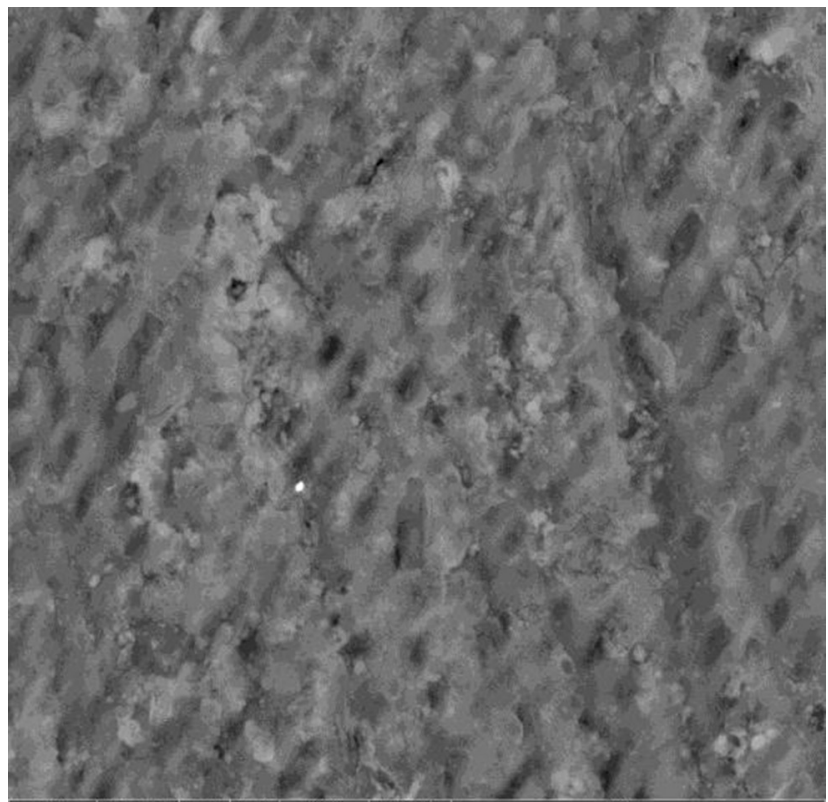

Fig. 2 Environmental scanning electron microscope showing dentin surface treated with sodium fluoride for 1 minute with almost complete obliteration of dentinal tubules and peritubular dentin.

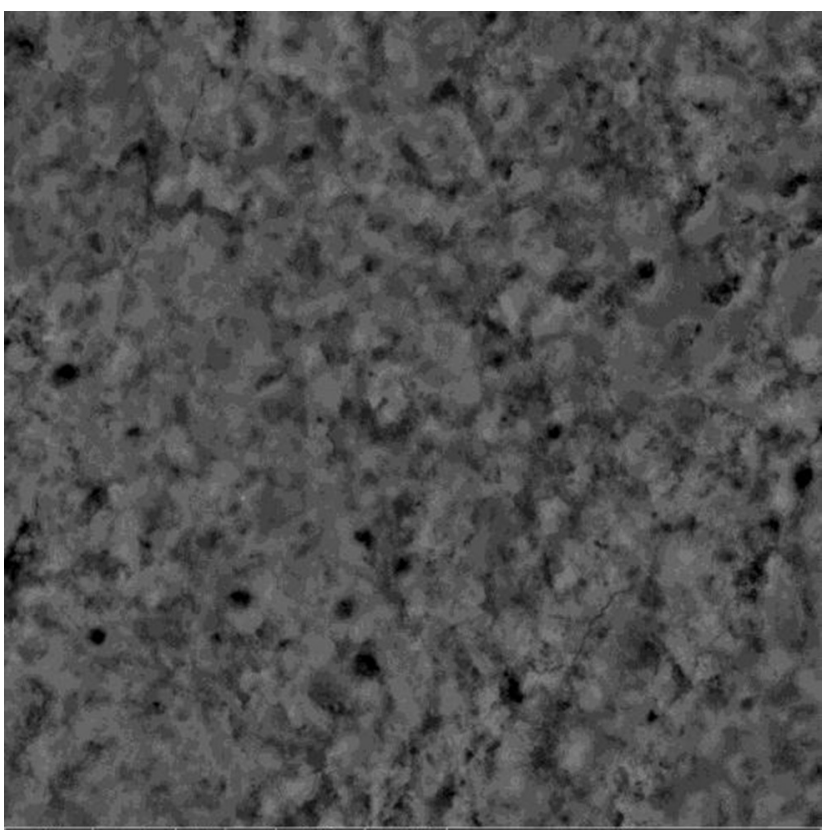

Fig. 3 Environmental scanning electron microscope showing dentin surface treated with sodium fluoride for 5 minute with almost complete obliteration of dentinal tubules and peritubular dentin.

specimens, respectively, revealed almost complete obliteration of dentinal tubules and intertubular dentin. However, a smoother and more homogenous surface was revealed by the GCE specimens.

\section{EDX Analysis}

- Table 3 demonstrates the effect of different treatment solutions at 2 and 5 minutes on the mean $\mathrm{Ca}^{2+}$ content of

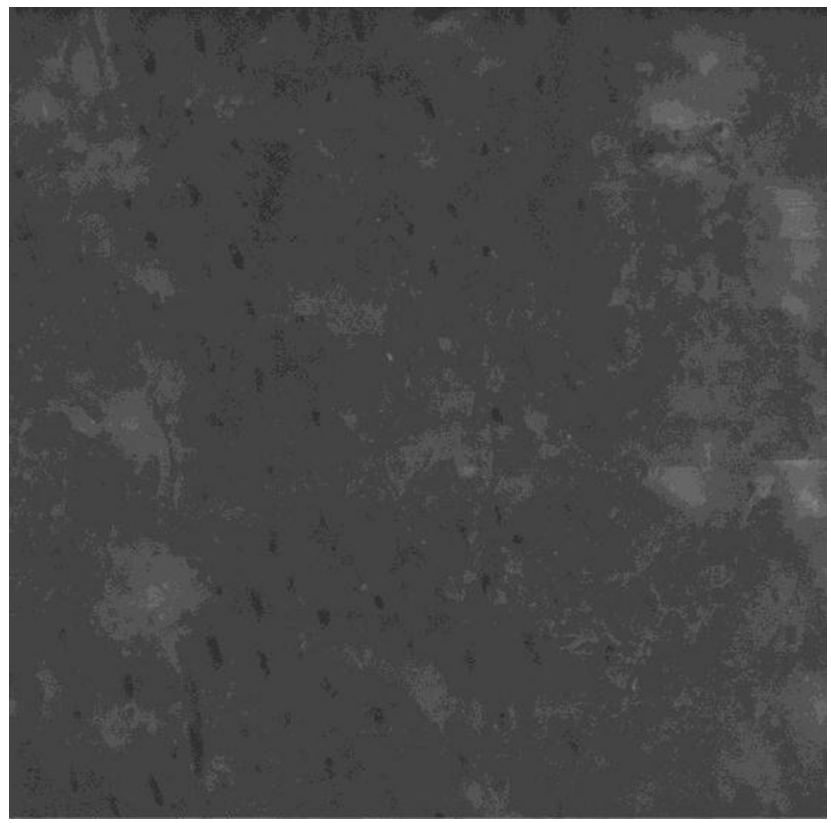

Fig. 4 Environmental scanning electron microscope showing dentin treated with Galla chinensis extract for 1 minute with almost complete obliteration of dentinal tubules and peritubular and smoother and more homogenous surface dentin.

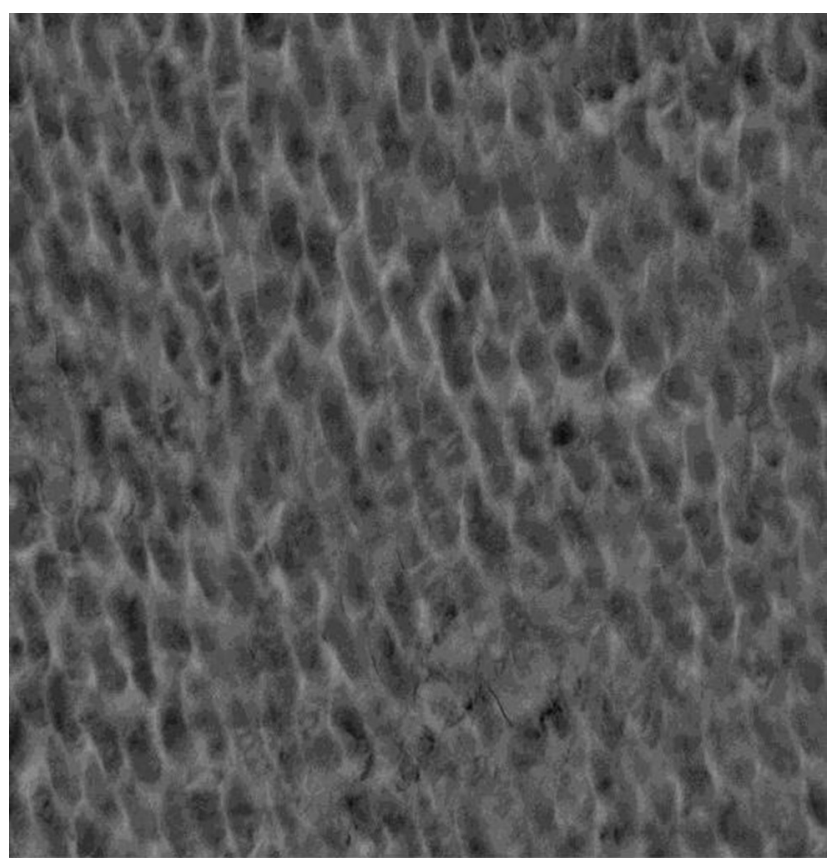

Fig. 5 Environmental scanning electron microscope showing dentin treated with Galla chinensis extract for 5 minutes with almost complete obliteration of dentinal tubules and peritubular.

dentin (mean \pm SD and level of significance) for all groups. They demonstrate that the NaF recorded the highest mean value followed by GCE. Meanwhile, DW group recorded the lowest mean value. The difference between $\mathrm{NaF}$ and GCE groups was statistically nonsignificant. Meanwhile, there was a significant difference between both of them and DW group. Regarding the time, the 5-minute immersion for $\mathrm{NaF}$ and DW groups recorded higher mean $\mathrm{Ca}^{2+}$ value of dentin 
Table 3 Effect of different immersing solutions on the mean Ca content of dentin

\begin{tabular}{|c|c|c|c|c|c|c|c|c|c|c|}
\hline & & & & \multicolumn{3}{|c|}{ Immersing solution } & \multirow{2}{*}{$\begin{array}{l}\text { ANOVA } \\
p \text {-Value }\end{array}$} & \multicolumn{3}{|c|}{ Post hoc } \\
\hline & & & & DW & $\mathrm{NaF}$ & GCE & & P1 & P2 & P3 \\
\hline \multirow[t]{6}{*}{ Time } & \multirow[t]{3}{*}{$1 \mathrm{~min}$} & Baseline & Mean \pm SD & $\begin{array}{l}38.83 \pm \\
3.45\end{array}$ & $\begin{array}{l}38.83 \pm \\
3.45\end{array}$ & $\begin{array}{l}38.83 \pm \\
3.45\end{array}$ & 1.00 & & & \\
\hline & & Demineralization & Mean \pm SD & $\begin{array}{l}29.91 \pm \\
4.63\end{array}$ & $\begin{array}{l}28.63 \pm \\
3.05\end{array}$ & $\begin{array}{l}28.77 \pm \\
2.51\end{array}$ & 0.087 & & & \\
\hline & & Remineralization & Mean \pm SD & $\begin{array}{l}32.57 \pm \\
1.27\end{array}$ & $\begin{array}{l}41.39 \pm \\
0.538\end{array}$ & $\begin{array}{l}42.68 \pm \\
0.94\end{array}$ & $0.008^{\mathrm{a}}$ & $0.01^{\mathrm{a}}$ & $0.026^{\mathrm{a}}$ & 0.87 \\
\hline & \multirow[t]{3}{*}{$5 \min$} & Baseline & Mean \pm SD & $\begin{array}{l}38.83 \pm \\
3.45\end{array}$ & $\begin{array}{l}38.83 \pm \\
3.45\end{array}$ & $\begin{array}{l}38.83 \pm \\
3.45\end{array}$ & 1.00 & & & \\
\hline & & Demineralization & Mean \pm SD & \begin{tabular}{|l}
$31.04 \pm$ \\
5.33
\end{tabular} & $\begin{array}{l}30.10 \pm \\
1.40\end{array}$ & $\begin{array}{l}30.76 \pm \\
2.88\end{array}$ & 0.9 & & & \\
\hline & & Remineralization & Mean \pm SD & $\begin{array}{l}33.17 \pm \\
1.33\end{array}$ & $\begin{array}{l}41.52 \pm \\
1.38\end{array}$ & $\begin{array}{l}40.19 \pm \\
3.69\end{array}$ & $<0.001^{\mathrm{a}}$ & $0.001^{\mathrm{a}}$ & $<0.001^{\mathrm{a}}$ & 0.8 \\
\hline
\end{tabular}

Abbreviations: ANOVA, analysis of variance; DW, distilled water; GCE, Galla chinensis extract; NaF, sodium fluoride; SD, standard deviation. Notes: P1: significance between DW and NaF; P2: significance between DW and GCE; P3: significance between NaF and GCE.

than the 1-minute immersion, with no statistical significant difference between both times for each group. Meanwhile, for GCE groups, the 1-minute immersion recorded higher mean $\mathrm{Ca}^{2+}$ content value of dentin than the 5 -minute immersion with no statistical significant difference between both times.

\section{Discussion}

Nowadays, dental caries management is based on conservative and preventive approaches. ${ }^{24}$ Different materials and methods are currently being evaluated to achieve newer approaches for the remineralization of demineralized dentin that will aid in treating dentin caries and dentin hypersensitivity. ${ }^{25}$ Previous reports have shown a major role of many commercially available products in enhancement of dental remineralization. ${ }^{26-28}$ But none of these agents in spite of being effective in dentin remineralization proved to be an ideal, highlighting an urgent need to seek novel and alternative strategies..$^{14,22,28}$ Recently, there has been a worldwide interest in active compounds derived from natural products which may have potential therapeutic uses in dentistry. ${ }^{29,30}$

GCE, a natural traditional Chinese medicine, is potentially a very interesting agent. Previous studies have shown that the raw aqueous extract of GCE is capable of inhibiting demineralization of enamel and enhancing remineralization..$^{13,31,32}$ Also, it was proved to have effective antibacterial role, ${ }^{33}$ but limited studies are performed on its effect on dentin remineralization. The effect of GCE on remineralization of early dentin lesion was evaluated in the current study through measuring SMH of dentin as an indirect method for determining changes in mineral content. Also, micromorphological and elemental analyses of the specimens were performed as confirmatory methods for the microhardness results. ${ }^{34}$

In the current study, the highest mean SMH and $\mathrm{Ca}^{2+}$ content values of dentin were recorded by $\mathrm{NaF}$ group; however, there was not any significant difference with GCE groups. These results were confirmed by ESEM images, where photomicrograph of NaF- and GCE-treated dentin specimens surfaces showed almost complete obliteration of dentinal tubules and intertubular dentin with a smoother surface especially in GCE group. ${ }^{35}$ This could be explained on the basis of presence of high organic matrix content in dentin, the potential of GCE to promote the remineralization of initial dentin carious lesions by deposit of $\mathrm{Ca}^{+2}$ ions from the complex "dentin organic matrix-GCE- $\mathrm{Ca}^{+2}$ " that enhance the mineral ion deposition in the GCE. ${ }^{36}$ This could boost the surface properties of dentin, such as SMH and $\mathrm{Ca}^{+2}$ content of dentin.

Regarding the time of immersion of dentin specimens in each corresponding remineralizing solution, the 5-minute immersion for NaF group recorded higher mean SMH and calcium content values of dentin than the 1-minute immersion with no statistical significant difference between them. This finding could be explained on the basis that fluoride increases the SMH by time; in later stages, the cycle leveled out and reached a plateau. ${ }^{37}$ So, fluoride may affect the mineral deposition in the outer enamel, but did not affect mineral precipitation in the inner enamel and dentin significantly. ${ }^{38}$

In contrast to the GCE groups, the 1-minute immersion recorded higher mean SMH and calcium content values of dentin than the 5-minute immersion with no statistical significant difference between them. These results could explain the GCE formed of different polyphenol compounds, which might slow down the remineralization of dentin surface by time, and offer more channels for ion transferring through the surface layer to the lesion body. ${ }^{39}$

\section{Conclusion}

Under the limitations of the current study, GCE could be used as an effective natural alternative for dentin remineralization.

\section{Conflict of Interest}

None declared. 


\section{References}

1 Robinson C, Shore RC, Bonass WA, Brookes SJ, Boteva E, Kirkham J. Identification of human serum albumin in human caries lesions of enamel: the role of putative inhibitors of remineralisation. Caries Res 1998;32(3):193-199

2 Featherstone JD. The continuum of dental caries-evidence for a dynamic disease process. J Dent Res 2004;83 Spec No $\mathrm{C}: \mathrm{C} 39-\mathrm{C} 42$

3 Mukai Y, ten Cate JM. Remineralization of advanced root dentin lesions in vitro. Caries Res 2002;36(4):275-280

4 Brar GS, Arora AS, Khinda VIS, Kallar S, Arora K. Topographic assessment of human enamel surface treated with different topical sodium fluoride agents: scanning electron microscope consideration. Indian J Dent Res 2017;28(6):617-622

5 Featherstone JD. Caries prevention and reversal based on the caries balance. Pediatr Dent 2006;28(2):128-132, discussion 192-198

6 Philip N. State of the art enamel remineralization systems: the next frontier in caries management. Caries Res 2019;53(3):284-295

7 Deng DM, van Loveren C, ten Cate JM. Caries-preventive agents induce remineralization of dentin in a biofilm model. Caries Res 2005;39(3):216-223

8 Bassin EB, Wypij D, Davis RB, Mittleman MA. Age-specific fluoride exposure in drinking water and osteosarcoma (United States) Cancer Causes Control 2006;17(4):421-428

9 Abdullah AZ, Strafford SM, Brookes SJ, Duggal MS. The effect of copper on demineralization of dental enamel. J Dent Res 2006;85(11):1011-1015

10 Iijima M, Du C, Abbott C, Doi Y, Moradian-Oldak J. Control of apatite crystal growth by the co-operative effect of a recombinant porcine amelogenin and fluoride. Eur J Oral Sci 2006;114(Suppl 1) :304-307, discussion 327-329, 382

11 Xie Q, Li J, Zhou X. Anticaries effect of compounds extracted from GCE in a multispecies biofilm model. Oral Microbiol Immunol 2008;23(4):459-465

12 Chu JP, Li JY, Hao YQ, Zhou XD. Effect of compounds of Galla chinensis on remineralisation of initial enamel carious lesions in vitro. J Dent 2007;35(5):383-387

13 Zou L, Zhang L, Li J, et al. Effect of Galla chinensis extract and chemical fractions on demineralization of bovine enamel in vitro. J Dent 2008;36(12):999-1004

14 Huang S, Gao S, Cheng L, Yu H. Combined effects of nano-hydroxyapatite and Galla chinensis on remineralisation of initial enamel lesion in vitro. J Dent 2010;38(10):811-819

15 Cheng L, ten Cate JM. Effect of Galla chinensis on the in vitro remineralization of advanced enamel lesions. Int J Oral Sci 2010;2(1):15-20

16 Zhang L, Xue J, Li J, et al. Effects of Galla chinensis on inhibition of demineralization of regular bovine enamel or enamel disposed of organic matrix. Arch Oral Biol 2009;54(9):817-822

17 Zhang L, Zou L, Li J, et al. Effect of enamel organic matrix on the potenrial of Galla Chinensis to promote the remineralization of initial enamel carious lesion in vitro. Biomed Mater 2009;4(3): 034102

18 Deng M, Dong X, Zhou X, Wang L, Li H and Xu X. Characterization of dentin matrix bio modified by Galla chinensis extract. JOE 2013;39(4):542-547

19 Belli S, Erdemir A, Ozcopur M, Eskitascioglu G. The effect of fibre insertion on fracture resistance of root filled molar teeth with MOD preparations restored with composite. Int Endod J 2005;38(2):73-80

20 Akman S, Akman M, Eskitascioglu G, Belli S. Influence of several fibre-reinforced composite restoration techniques on cusp movement and fracture strength of molar teeth. Int Endod J 2011;44(5):407-415
21 Kirsten GA, Takahashi MK, Rached RN, Giannini M, Souza EM. Microhardness of dentin underneath fluoride-releasing adhesive systems subjected to cariogenic challenge and fluoride therapy. J Dent 2010;38(6):460-468

22 Moloney VS, Meyers IA, Rintou L, Symons AL. The effect of remineralization treatments on demineralized dentin, an in vitro study. J Dent Oral Med 2014;2(1):1-8

23 Cheng L, Li J, Hao Y, Zhou X. Effect of compounds of Galla chinensis and their combined effects with fluoride on remineralization of initial enamel lesion in vitro. J Dent 2008;36(5):369-373

24 Savas S, Kavrìk F, Kucukyìlmaz E. Evaluation of the remineralization capacity of CPP-ACP containing fluoride varnish by different quantitative methods. J Appl Oral Sci 2016;24(3):198-203

25 Berkathullah M, Farook MS, Mahmoud O. The effectiveness of remineralizing agents on dentinal permeability. BioMed Res Int 2018;2018:4072815

26 Almohefer SA, Levon JA, Gregory RL, Eckert GJ, Lippert F. Caries lesion remineralization with fluoride toothpastes and chlorhexidine - effects of application timing and toothpaste surfactant. J Appl Oral Sci 2018;26:e20170499

27 Tschoppe P, Zandim DL, Martus P, Kielbasa AM. Enamel and dentin remineralization by nano-hydroxyapatite toothpastes. J Dent 2011;39(6):430-437

28 Zhong Y, Liu J, Li X, et al. Effect of a novel bioactive glass-ceramic on dentinal tubule occlusion: an in vitro study. Aust Dent J 2015;60(1):96-103

29 Groppo FC, Bergamaschi Cde, Cogo K. Franz-Montan M, Motta RH, de Andrade ED. Use of phytotherapy in dentistry. Phytother Res 2008;22(8):993-998

30 Newman DJ. Natural products as leads to potential drugs: an old process or the new hope for drug discovery? J Med Chem 2008;51(9):2589-2599

31 Cheng L, Li JY, Hao YQ, Zhou XD: Effect of compounds of Galla chinensis on remineralization of enamel surface in vitro. Arch Oral Biol 2010;55:435-440

32 Chu JP, Li JY, Hao YQ, Zhou XD. Effect of compounds of Galla chinensis on remineralisation of initial enamel carious lesions in vitro. J Dent 2007;35(5):383-387

33 Huang X, Deng M, Liu M, et al. Comparison of composition and anticaries effect of Galla chinensis extracts with different isolation methods. Open Dent J 2017;11:447-459

34 Angker L, Nockolds C, Swain MV, Kilpatrick N. Correlating the mechanical properties to the mineral content of carious dentine-a comparative study using an ultra-micro indentation system (UMIS) and SEM-BSE signals. Arch Oral Biol 2004;49(5):369-378

35 Xia Y, Yang ZY, Li YH, Zhou Z. The Effects of a toothpaste containing the active ingredients of Galla chinensis and sodium fluoride on dentin hypersensitivity and sealing of dentinal tubules: an in vitro study and an eight-week clinical study in 98 patients. Med Sci Monit 2020;26:e920776

36 Deng M, Dong X, Zhou X, Wang L, Li H, Xu X. Characterization of dentin matrix biomodified by Galla chinensis extract. J Endod 2013;39(4):542-547

37 Ahmadi Zenouz G, Ezoji F, Enderami SA, Khafri S. Effect of fluoride, casein phosphopeptide-amorphous calcium phosphate and casein phosphopeptide-amorphous calcium phosphate fluoride on enamel surface microhardness after microabrasion: An in vitro study. J Dent (Tehran) 2015;12(10):705-711

38 ten Cate JM. Remineralization of caries lesions extending into dentin. J Dent Res 2001;80(5):1407-1411

39 Zhang TT, Guo HJ, Liu XJ, Chu JP, Zhou XD. Galla chinensis compounds remineralize enamel caries lesions in a rat model. Caries Res 2016;50(2):159-165 